\title{
Pemanfaatan Film Sebagai Peningkatan Media Promosi Pada Tempat Wisata
}

\author{
Dewi Immaniar Desrianti ${ }^{* 1}$, Ruli Supriati ${ }^{2,}$, Kivti Herdiana ${ }^{3}$ \\ ${ }^{123}$ Program Studi Teknik Informatika, Fakultas Sains dan Teknologi, Universitas Raharja

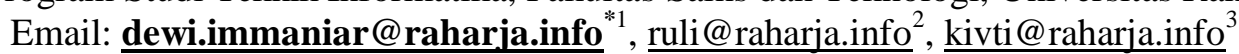

\begin{abstract}
Abstrak
Perkembangan zaman saat ini berpengaruh terhadap berkembang nya teknologi informasi dan komunikasi. Salah satu media pendukung untuk menyampaikan informasi yang efektif yaitu media promosi. Saat ini banyak tempat - tempat wisata yang memanfaatkan Film sebagai media promosi. Film saat ini banyak digemari oleh kalangan manapun karena Film menampilkan penyampaian cerita yang berbentuk audiovisual dan memiliki makna atau arti serta dikemas dengan teknik sinematografi yang indah dan menarik. Permasalahannya adalah dalam menginformasikan dan mempromosikan Wisata Alam Sevillage ini hanya menggunakan media cetak seperti brosur, pamflet keterangan harga tiket, nameboard dan foto-foto yang diunggah ke sosial media Wisata Alam Sevillage, sehingga diperlukan pemanfaatan Film untuk peningkatan media promosi pada Wisata Alam Sevillage. Tujuan penelitian ini adalah untuk membantu pihak pengelola dalam peningkatan media promosi untuk menarik minat berkunjung ke Wisata Alam Sevillage melalui strategi promosi pada sosial media Facebook, Instagram, Youtube, dan promosi ke relasi. Manfaat penelitian ini yaitu melalui Film ini, Wisata Alam Sevillage dapat meningkatkan jumlah wisatawan lokal maupun mancanegara yang berkunjung, serta meningkatkan pencapaian target pemasaran. Metode penelitiannya yaitu, Pengumpulan Data, Analisa SWOT, Analisa Perancangan Media dan Konsep Produksi Media (KPM). Hasil dari penelitian ini nanti nya akan diimplementasikan ke media sosial seperti Facebook, Instagram dan Youtube untuk membantu mempromosikan Wisata Alam.
\end{abstract}

Kata kunci - Film, Promosi, Wisata

\section{Abstract}

The development of the current era affects the growth of information and communication technology. One of the supporting media to convey effective information is promotional media. Nowadays, many tourist spots make use of Film as promotional media. Movies nowadays are much favored by many circles because the Film features an audiovisual-shaped story that has meaning or meaning and is packed with beautiful and interesting cinematography techniques. The problem is to inform and promote Sevillage nature tourism only use print media such as brochures, ticket price pamphlets, name boards, and photos uploaded to social media Sevillage nature tourism, so the need to use Film to increase promotional media in Sevillage natural tourism. The purpose of this research is to assist the maintainer in improving promotional media to attract a visit to Sevillage nature tourism through a promotional strategy on social media Facebook, Instagram, Youtube, and promotion to relationships. The benefits of this research through this Film, Wisata Alam Sevillage can increase the number of local and foreign tourists who visit and increase the achievement of target marketing. Its research methods are Data collection, SWOT analysis, Media planning analysis, and Media production concept (KPM). The results of this research will later be implemented on social media such as Facebook, Instagram, and Youtube to help promote Sevillage nature tourism.

Keyword - Movies, Promotions, Travel

143 


\section{PENDAHULUAN}

Perkembangan zaman saat ini berpengaruh terhadap berkembangnya teknologi informasi dan komunikasi yang sangat dibutuhkan sebagai media penyampaian. Salah satu media pendukung untuk menyampaikan informasi yang efektif yaitu media promosi. Saat ini bukan hanya instansi atau perusahaan yang mempromosikan tentang instansi atau perusahaan tersebut memanfaatkan media Film, banyak tempat - tempat wisata juga memanfaatkan media Film untuk mempromosikan keindahan dan keunggulan yang ada dalam wisata tersebut.

Film adalah media audiovisual yang dimanfaatkan untuk menginformasikan dan mempromosikan secara detail dengan menampilkan penyampaian cerita yang terdapat makna atau arti serta dikemas dengan teknik sinematografi yang indah dan menarik bagi audience.

Kabupaten Cianjur yang berada di Provinsi Jawa Barat memiliki luas wilayah 3.432,96 $\mathrm{km}^{2}$ dengan 32 Kecamatan dan 348 Kelurahan, memiliki 2.256.589 ribu jiwa pada tahun 2016, merupakan tempat tujuan wisata yang menarik.

Wisata Alam Sevillage dibawah naungan perusahaan PT. Indo Othaim Internasional. Wisata Alam Sevillage merupakan salah satu tempat wisata alam yang berlokasi di Jl. Ziwa Besar Kp. Parabon, RT 04/RW 03 Desa Ciloto, Kecamatan Cipanas, Kabupaten Cianjur, Jawa Barat ini menjadi tempat wisata yang bertemakan alam sehingga wisatawan bisa berwisata dengan tenang, nyaman, dan menyenangkan dalam mengisi liburan dengan berbagai kegiatan seperti wahana spot foto yang disediakan yaitu Sky Bike, Sky Swing, Flying Fox, Helikopter, Adrenaline Swing, dan Helium yang menjadi keunggulan.

Permasalahannya adalah dalam menginformasikan dan mempromosikan Wisata Alam Sevillage ini hanya menggunakan media cetak seperti brosur, pamflet keterangan harga tiket, dan nameboard Wisata Alam Sevillage, sehingga diperlukan pemanfaatan Film sebagai peningkatan media promosi untuk menarik minat wisatawan berkunjung ke Wisata Alam Sevillage.

Tujuan penelitian ini adalah untuk membantu pihak pengelola dalam meningkatkan daya tarik wisatawan pada Wisata Alam Sevillage melalui strategi promosi pada social media Facebook, Instagram, Youtube, dan promosi ke relasi.

Untuk itu diperlukan sebuah solusi dari pemecahan masalah di atas, dengan melakukan pemanfaatan melalui media lain seperti pemanfaatan Film ini. Dengan adanya pemanfaatan Film ini, pihak pengelola dengan mudah memperkenalkan jenis - jenis kegiatan, wahana dan keunggulan yang terdapat pada Wisata Alam Sevillage sehingga wisatawan lebih mudah mengetahui apa yang ada didalamnya dan nantinya Film ini akan diimplementasikan melalui Youtube channel dan social media Wisata Alam Sevillage.

Adapun penelitian yang berkaitan dengan pemanfaatan Film ini seperti penelitian yang dilakukan oleh Septian, dkk. (2017) "[1] "Film Dokumenter PTI : Rumahku (Sebuah Catatan, Sebuah Kisah)". Tujuan dari penelitian ini yaitu untuk menghasilkan rancangan dan mengimplementasikan film dokumenter PTI : Rumahku (Sebuah Catatan, Sebuah Kisah). Dalam penelitian ini menggunakan Metode perancangan melalui observasi dan wawancara kemudian Metode cyclic strategy atau strategi berputar konsep perancangan

Berikutnya penelitian yang dilakukan Santyadiputra, dkk (2017) "Film Dokumenter Genggong "Sebuah Instrumen Musik Kuno". Tujuan dari penelitian ini yaitu untuk menghasilkan rancangan dan mengimplementasikan hasil rancangan Film Dokumenter Genggong Sebuah Instrumen Musik Kuno. Dalam penelitian tersebut menghasilkan Film Dokumenter, yang menggunakan 2 metode penelitian seperti pengumpulan data dan KPM (Konsep Produksi Media).

Kemudian, ada penelitian yang dilakukan oleh Hariyanto (2018) [3] "Perancangan Promosi Wisata Kota Medan Dalam Bentuk Media Audio Visual". Tujuan penelitian ini untuk menciptakan promosi yang efektif dan informatif dalam bentuk media audio visual. Hasil dari penelitian tersebut adalah Media promosi dalam bentuk audio visual. Metode yang digunakan yaitu, Analisa Permasalahan, Pengumpulan data, dan Analisis SWOT.

Selanjutnya penelitian yang dilakukan oleh Saleh, dkk (2016) "Film yang Efektif 
Sebagai Media Promosi Kesehatan bagi Masyarakat". Penelitian ini bertujuan untuk mengeksplorasi perancangan dan pembuatan media promosi kesehatan film pendek yang efektif tentang rokok dan bahayanya. Hasil dari penelitian tersebut adalah Film yang efektif sebagai media promosi kesehatan bagi masyarakat. Metode yang digunakan metode kualitatif.

Lalu ada penelitian yang dilakukan oleh Sari, dkk (2017) ${ }^{[5]}$ "Pemanfaatan Film Perjuangan untuk Meningkatkan Pemahaman Konsep Bela Negara Siswa". Tujuan diadakannya penelitian ini adalah mendeskripsikan pemanfaatan film perjuangan dalam meningkatkan pemahaman konsep Bela Negara. Metode yang digunakan dalam penelitian ini adalah metode deskriptif dengan pendekatan kualitatif dengan sampel berjumlah 26 responden.

\section{METODE PENELITIAN}

Beberapa metode penelitian yang digunakan untuk (Judul Jurnal), yaitu: (1) Metode Pengumpulan Data, yaitu metode yang digunakan untuk mendapatkan data dengan jalan pengamatan (Observasi), interview ataupun dari kajian pustaka. (2) Analisa Perancangan Media yaitu Software apa saja yang dipakai untuk mengedit video. (3) Konsep Produksi Media (KPM). Pembuatan media Film ini melalui beberapa proses perancangan agar mendapat gambaran tentang project yang dibuat, sehingga memudahkan dalam membuat Film ini. Tahapan yang dilakukan dalam Konsep Produksi Media (KPM) adalah Pre Production, Production dan Post Production.

\section{HASIL DAN PEMBAHASAN}

\subsection{Pre Production}

Pre Production merupakan proses awal atau langkah awal dimulainya suatu karya yang diantaranya berupa pengumpulan data dan elemen yang berkaitan dengan produksi. Seperti menentukan ide/gagasan, sinopsis, script writing, storyboard, rundown, penyusunan crew, time schedule, dan mempersiapkan alat - alat pendukung yang dibutuhkan selama proses produksi. Berikut merupakan gambaran dari tahap Pre Production :

1. Ide/Gagasan

Ide atau Gagasan merupakan sebuah rencana awal dari proses pre production, hal itu merupakan hal yang mendasar untuk perancangan sebuah karya Film. Sebuah ide atau gagasan yang telah tercipta kemudian dikembangkan lagi dengan mengumpulkan data-data berdasarkan masalah yang ada. Kemudian dalam penelitian ini konsep yang dibutuhkan dalam pemanfaatan Film pada Wisata Alam Sevillage ini menampilkan informasi tentang keunggulan yang dimiliki Wisata Alam Sevillage dengan konsep yang menarik agar dapat meningkatkan wisatawan.

2. Sinopsis

Sinopsis merupakan suatu ringkasan cerita dari awal hingga akhir yang dibentuk menjadi cerita singkat, padat dan jelas tanpa menghilangkan beberapa unsur penting dalam keseluruhan cerita. Tujuan pembuatan sinopsis agar mendapatkan gambaran utuh dari urutan cerita dalam naskah. Berikut adalah sinopsis Film pada Wisata Alam Sevillage:

"Dito sedang asyik memakan jajanan nya dibawah pohon yang rindang, kemudian saat Dito sedang berkeliling di taman dia mendengar suara alunan lagu entah darimana datangnya. Dito pun mengikuti suara alunan lagu tersebut hingga saat sedang berjalan 
Dito terjatuh kedalam semak-semak yang membawanya ke dunia lain. Lalu Dito pun terdampar di tempat yang tidak pernah kunjungi. Dito bertemu dengan seorang pria yang mengajaknya bermain-main di tempat tersebut. Disana terdapat berbagai wahana, mulai dari wahana Helikopter, Helium, Sky Bike, Sky Swing, dan Flying fox pun Dito sambangi. Dito merasa senang sekali bermain di tempat tersebut hingga matahari terbenam dan pria tersebut menyuruh Dito untuk kembali kerumah karena waktunya sudah selesai. Dengan berat hati Dito pun pulang melewati semak-semak tempat Dito datang."

3. Narasi

Narasi merupakan pengembangan dari paragraf sebuah tulisan yang dijabarkan secara teratur dari urutan awal, tengah, akhir yang memiliki unsur dengan bentuk berupa tema, latar, setting, dan karakter. Narasi yang direkam dalam menggantikan suara suatu tokoh karakter sering disebut dubbing. Berikut narasi yang dalam video profile berbasis film akan dijadikan dubbing:

"Pada suatu pagi/terlihat seorang anak yang tidak merasa bahagia dengan kehidupannya/terlihat murung/namun/sedikit aktif/kegiatannya pun hanya sebatas/bermain/berjalan diatas rumput/memakan snack yang ada di tangannya/bermain dengan buah pinus yang ada di depannyall Sampai akhirnya sebuah kejadian/merubah keadaan pada hari itu/l Ternyata/dia memasuki dunia yang tidak pernah didatangi sebelumnya// Dan/dia pun bertemu dengan paman Jenggi/Om Jenggi pun berkata/ternyata aku melihat seorang anak yang menyasar disini// Om Jenggi dengan gaya nyentriknya/merupakan salah satu penjaga yang ada di Sevillage inil/ Apa saja yang ada di dunia Sevillage ini?// Tentu saja ada balon raksasa yang membuat Dito melambaikan tangannya/dan selanjutnya ada ayunan raksasa yang membuat Dito berteriak/lalu Dito diajak menaiki helikopter yang terlihat palsu namun mengasyikan/dan Dito pun diajak menaiki ayunan yang terbuat dari akar buncis kata Om Jenggi/ dan Dito pun diajak menaiki flying fox dimana flying fox tersebut membuat Dito merasa terbang di angkasa/terakhir Dito diajak menaiki satu wahana yaitu sepeda yang membuat Dito merasa berdebar// Itulah pengalaman Dito/di dunia Sevillage yang sangat menakjubkan//"

4. Script Writing

Script Writing adalah sebuah rancangan ide dasar atau gagasan cerita yang ditulis secara detail atau rinci untuk mempermudah proses editing. Script writing pada project ini bisa dilihat pada Tabel 1 dibawah ini :

Tabel 1. Script Writing

\begin{tabular}{|c|l|l|}
\hline No & \multicolumn{1}{|c|}{ Visual } & \multicolumn{1}{c|}{ Audio } \\
\hline 1. & Menampilkan Video Footage drone & \\
\hline 2. & $\begin{array}{l}\text { Menampilkan Video Anak sedang duduk dibawah } \\
\text { Pohon }\end{array}$ & $\begin{array}{l}\text { Morning relaxing } \\
\text { Music }\end{array}$ \\
\hline 3. & Menampilkan Video Anak terjatuh saat berjalan & $\begin{array}{l}\text { Sound Effect } \\
\text { orang jatuh }\end{array}$ \\
\hline 4. & Menampilkan Bumper Judul Film & Music. \\
\hline 5. & $\begin{array}{l}\text { Menampilkan Video Paman menghampiri dan } \\
\text { mengajak bermain anak }\end{array}$ & $\begin{array}{l}\text { Garden ambient } \\
\text { sound }+ \text { Dialog. }\end{array}$ \\
\hline
\end{tabular}




\begin{tabular}{|c|l|l|}
\hline 6. & $\begin{array}{l}\text { Menampilkan Video Anak menaiki wahana Sky } \\
\text { Bike }\end{array}$ & Fun Music. \\
\hline 7. & $\begin{array}{l}\text { Menampilkan Video Paman mengantar pulang Anak } \\
\text { melewati semak-semak }\end{array}$ & Fun Music.. \\
\hline 8. & $\begin{array}{l}\text { Menampilkan Logo Wisata Alam Sevillage, } \\
\text { alamat, no telp, alamat dan media sosial. }\end{array}$ & \\
\hline
\end{tabular}

\section{Storyboard}

Storyboard merupakan sebuah sketsa/gambar yang disusun berurutan sesuai dengan jalan cerita. Dalam penyampaian ide dan jalan cerita umumnya menggunakan storyboard, agar yang melihat lebih mudah paham dengan informasi yang akan disampaikan, karena storyboard merupakan sebuah gambaran kasar mengikuti ilustrasi gambar yang disampaikan, sehingga menjadi persepsi yang sama dengan ide dan jalan cerita. Dilihat pada gambar 3, scene 1 menampilkan video footage drone dengan pengambilan gambar bird eye. Kemudian gambar 4, scene 2 menampilkan seorang anak yang sedang duduk dibawah pohon dengan pengambilan gambar long shot. Selanjutnya gambar 5, scene 3 menampilkan anak terjatuh ke semak-semak saat sedang berjalan dengan pengambilan gambar long shot. Berikutnya gambar 6 , scene 4 menampilkan bumper untuk judul Film nya. Lalu pada gambar 7, scene 5 menampilkan paman mengajak bermain anak tersebut dengan pengambilan gambar full shot. Pada gambar 8, scene 6 menampilkan anak menaiki wahana Sky Bike dengan angle kamera low angle. Untuk gambar 9, scene 7 menampilkan paman mengantar pulang anak dengan pengambilan gambar full shot. Dan terakhir pada gambar 10 scene 8 menampilkan Logo Wisata Alam Sevillage, alamat, no telp, alamat dan media sosial.

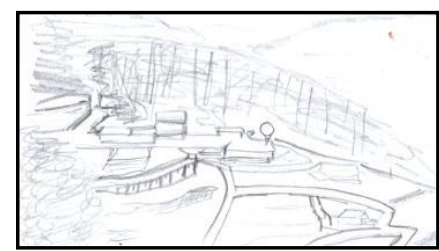

Gambar 3. Scene 1//Menampilkan Video Footage Drone/Day/Bird eye

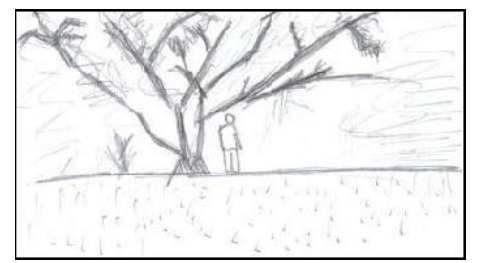

Gambar 5. Scene 3/EXT/Menampilkan Video Anak terjatuh saat berjalan/Long Shot

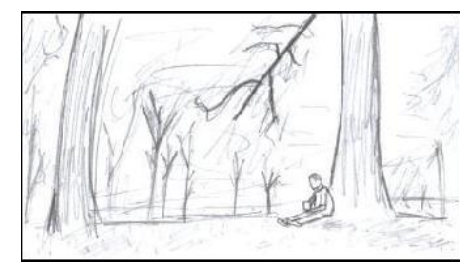

Gambar 4. Scene 2/EXT/Menampilkan Video Anak sedang duduk dibawah pohon/Day/Long Shot

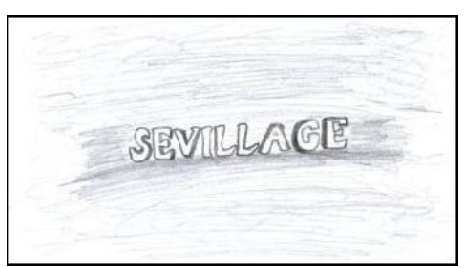

Gambar 6. Scene 4/Menampilkan Bumper Judul Film 


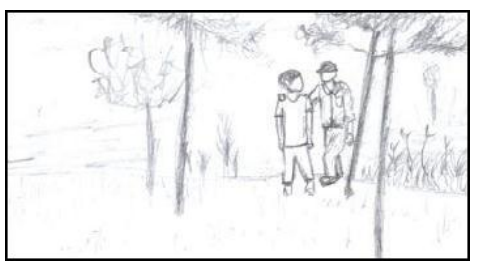

Gambar 7. Scene 5/EXT/Menampilkan

Video Paman menghampiri dan mengajak bermain anak/Day/Full Shot

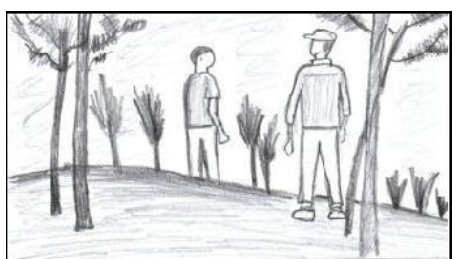

Gambar 9. Scene 7/EXT/Menampilkan Video Paman mengantar pulang Anak melewati semak-semak/Day/Full Shot

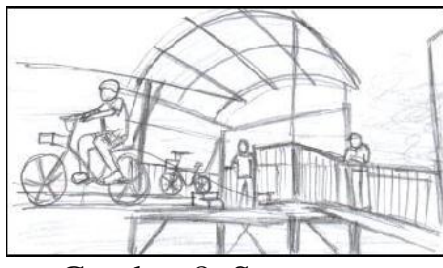

Gambar 8. Scene 6/EXT/Menampilkan Video Anak menaiki wahana Sky Bike/Day/Low Angle

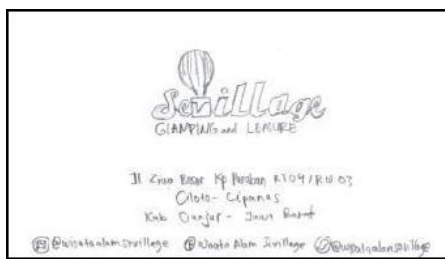

Gambar 10. Scene

8/Menampilkan Logo Wisata

Alam Sevillage, alamat, no telp, alamat dan media sosial.

6. Rundown

Rundown merupakan susunan inti cerita dengan rancangan durasi waktu yang sesuai. Rundown dari Film Wisata Alam Sevillage bisa dilihat pada tabel 2 berikut ini:

Tabel 2. Rundown

\begin{tabular}{|c|c|c|c|c|c|}
\hline No. & Scene & Location & Duration & INT/EXT & Description \\
\hline 1. & 2 & Taman 1 & $\begin{array}{c}\text { 00:00:05:36- } \\
\text { 00:00:13:09 }\end{array}$ & EXT & $\begin{array}{c}\text { Menampilkan Video Anak sedang duduk } \\
\text { dibawah pohon }\end{array}$ \\
\hline 2. & 3 & Taman 1 & $\begin{array}{c}00: 00: 35: 21- \\
00: 00: 47: 47 \\
\end{array}$ & EXT & $\begin{array}{c}\text { Menampilkan Video Anak terjatuh saat } \\
\text { berjalan }\end{array}$ \\
\hline 3. & 5 & Taman 2 & $\begin{array}{l}\text { 00:01:10:44- } \\
\text { 00:01:28:17 }\end{array}$ & EXT & $\begin{array}{l}\text { Menampilkan Video Paman menghampiri } \\
\text { dan mengajak bermain anak }\end{array}$ \\
\hline 4. & 7 & Taman 2 & $\begin{array}{c}\text { 00:03:16:33- } \\
\text { 00:03:39:18 }\end{array}$ & EXT & $\begin{array}{l}\text { Menampilkan Video Paman mengantar } \\
\text { pulang Anak melewati semak-semak }\end{array}$ \\
\hline 5. & 6 & $\begin{array}{l}\text { Wahana } \\
\text { Sky Bike } \\
\text { Sevillage }\end{array}$ & $\begin{array}{l}\text { 00:03:06:32- } \\
\text { 00:03:16:31 }\end{array}$ & EXT & $\begin{array}{c}\text { Menampilkan Video Anak menaiki wahana } \\
\text { Sky Bike }\end{array}$ \\
\hline
\end{tabular}

7. Penyusunan Crew

Dalam Penyusunan crew, dibutuhkan ketentuan dalam memberikan jobdesk pada crew, pada sebuah perancangan video di dalam penyusunan crew terdapat Sutradara, Camera Person, Audioman, Script Writer, Editor, dan Pemain. Berikut adalah susunan 
pemain dan crew yang terlibat dalam Film Wisata Alam Sevillage Ciloto terdapat pada tabel 3 dibawah ini:

Tabel 3. Susunan Crew

\begin{tabular}{|r|l|l|}
\hline 1. & Sutradara & Nama \\
\hline 2. & Camera Person 1 & Kivti Herdiana \\
\hline 3. & Camera Person 2 & Jody Ivander \\
\hline $\mathbf{4 .}$ & Audioman & Firmansyah Agustian \\
\hline $\mathbf{5 .}$ & Editor & Kivti Herdiana \\
\hline $\mathbf{6 .}$ & Script Writer & Kivti Herdiana \\
\hline $\mathbf{7 .}$ & Wardrobe & Della Nurasiah \\
\hline $\mathbf{8 .}$ & Dubber & Firmansyah Agustian \\
\hline $\mathbf{9 .}$ & Pemain Dito & Rizki Ardiansyah \\
\hline $\mathbf{1 0 .}$ & Pemain Paman & Aditiawarman \\
\hline
\end{tabular}

8. Analisa Perancangan Media

Dalam Film Wisata Alam Sevillage ini menggunakan software yang digunakan adalah: Adobe Premiere CC 2018, Adobe Audition CC 2018 dan Adobe After Effect CC 2018

9. Time Schedule

Time Schedule merupakan alokasi waktu yang diperkirakan untuk menyelesaikan proses produksi secara keseluruhan dengan waktu yang ditetapkan. Berikut adalah time schedule dalam pemanfaatan Film pada Wisata Alam Sevillage Ciloto ditampilkan pada tabel 4 berikut:

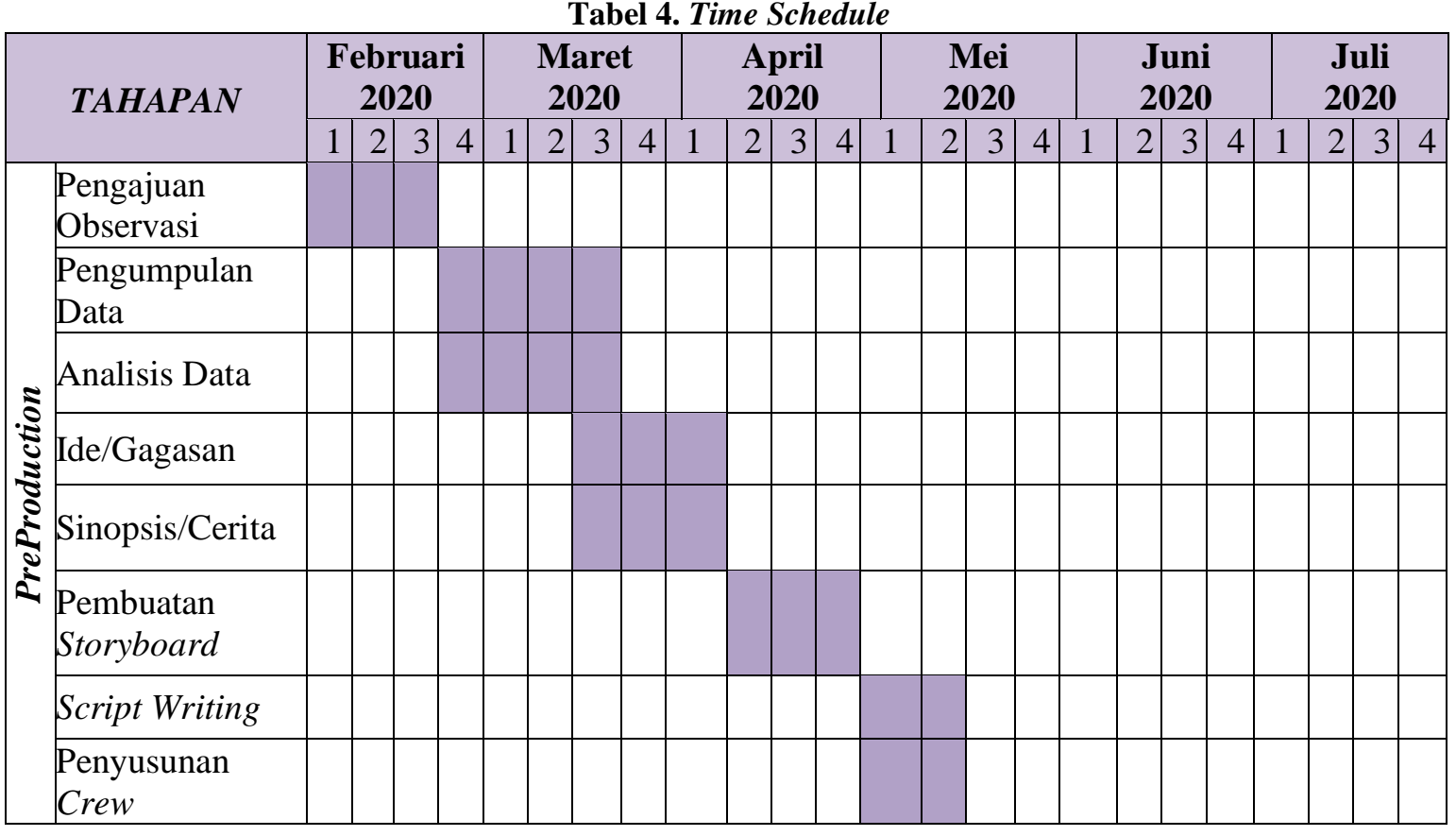


Print ISSN: 2723-1992

Online ISSN: 2723-200X

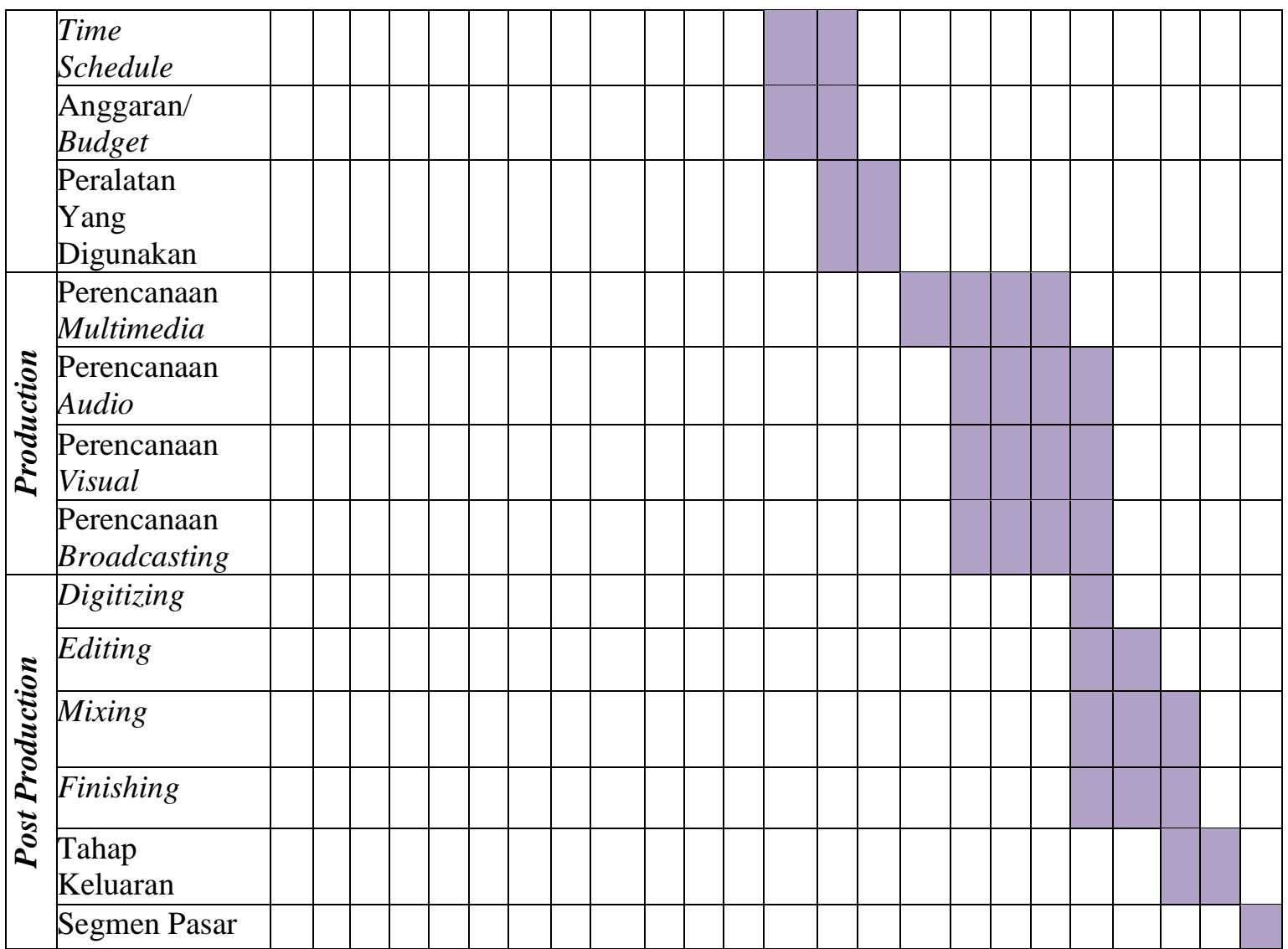

10. Peralatan yang digunakan

Dalam pembuatan Film pada Wisata Alam Sevillage Ciloto ini menggunakan peralatan seperti Camera Mirrorless Sony A7 Mark II, Camera Mirroless Sony A6000, Lensa Sony FE 16 - 35 mm, Lensa Tamron 17-28 mm, Tripod, Zhiyun Stabilizher, Zoom H5N Pro, Rode NTG 4\& Boom Pole, Memory Card 16 GB, Memory Card 64 GB, Laptop dan Flash Disk. Proses pengambilan video ini lebih banyak di luar ruangan.

\subsection{Production}

Production merupakan proses pengambilan gambar dengan kerjasama antara sutradara, crew, dan pemain untuk perwujudan dari Sinopsis, Storyboard dan Time Schedule yang sudah dibuat serta tahapan ini juga peran sutradara sangat dibutuhkan untuk mengatur talent yang terlibat agar sesuai dengan naskah. Setiap proses production pengambilan gambar atau shooting ada beberapa hal yang harus dipersiapkan dengan baik, seperti pada gambar dibawah ini gambar 11 memperlihatkan sedang mengambil audio untuk dialog dan gambar 12 memperlihatkan sedang mengambil gambar. 
Print ISSN: 2723-1992

Online ISSN: 2723-200X

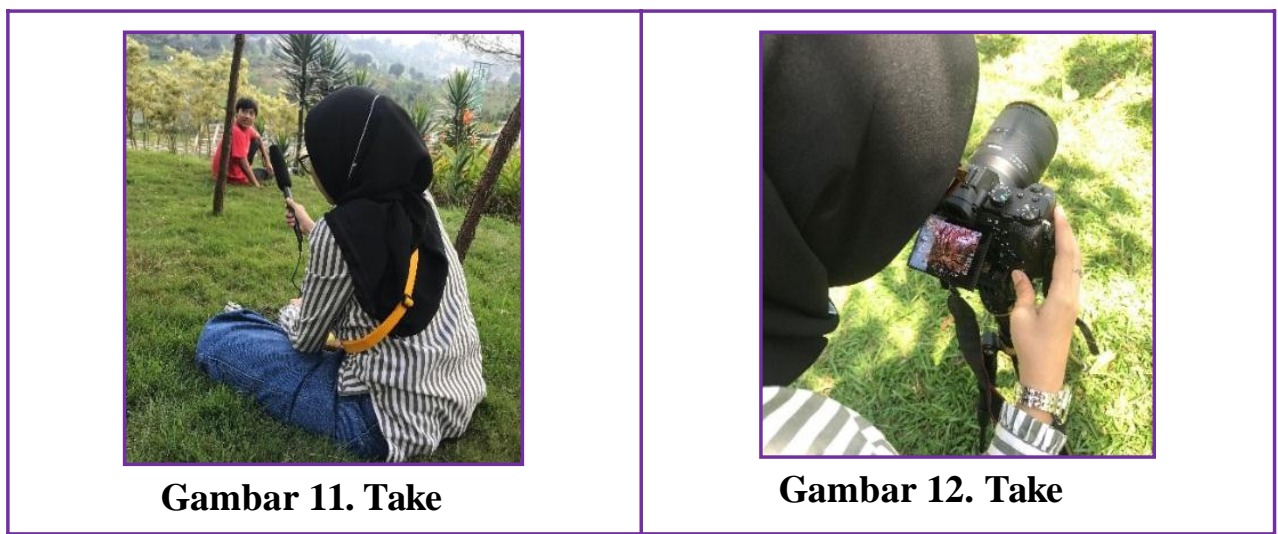

1. Program Visual

Tampilan Film ini dirancang pada saat pembuatan sinopsis. Berikut adalah tampilan isi Film yang telah dibuat pada saat proses Konsep Produksi Media (KPM).

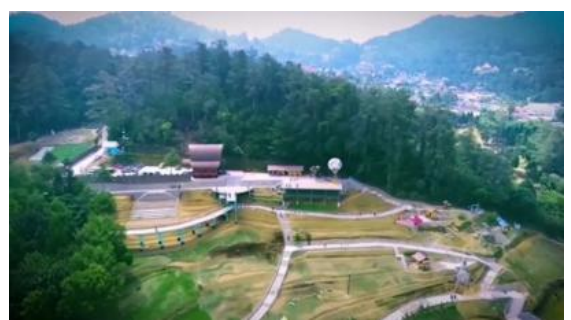

Gambar 13. Scene 1/Menampilkan Video Footage Drone/Day/Bird eye

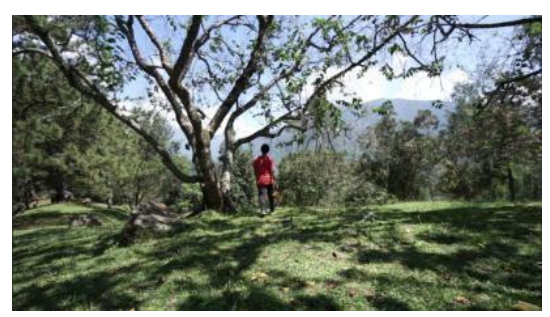

Gambar 15. Scene 3/EXT/Menampilkan Video Anak terjatuh saat berjalan/Day/Long Shot

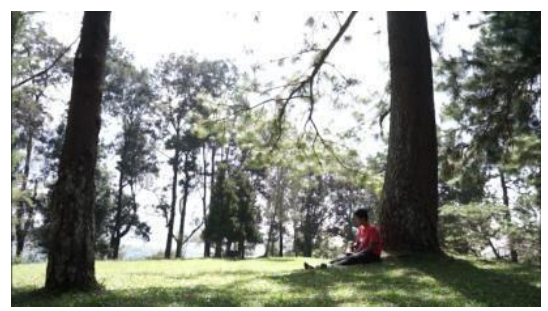

Gambar 14. Scene 2/EXT/Menampilkan Video Anak sedang duduk dibawah pohon/Day/Long Shot

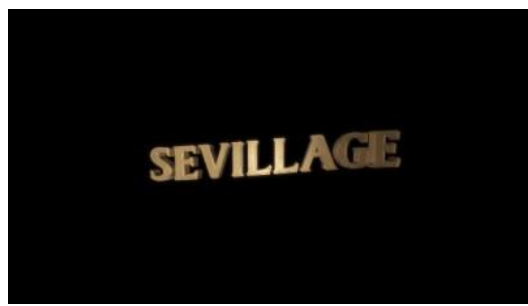

Gambar 16. Scene 4/ Menampilkan Bumper Judul Film 


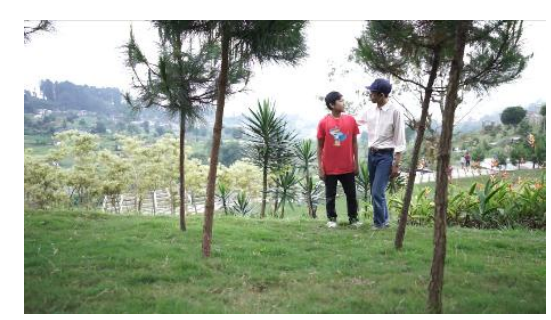

Gambar 17. Scene 5/EXT/Menampilkan

Video Paman menghampiri dan mengajak bermain anak/Day/Full Shot

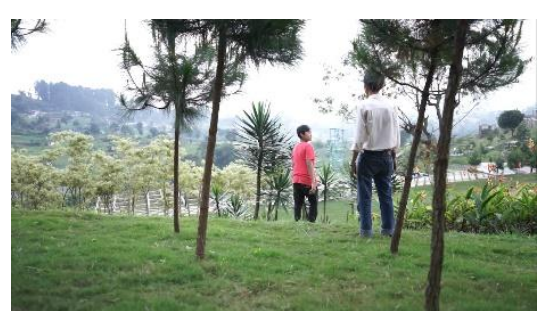

Gambar 19. Scene 7/EXT/Menampilkan Video Paman mengantar pulang Anak melewati semak-semak/Day/Full Shot

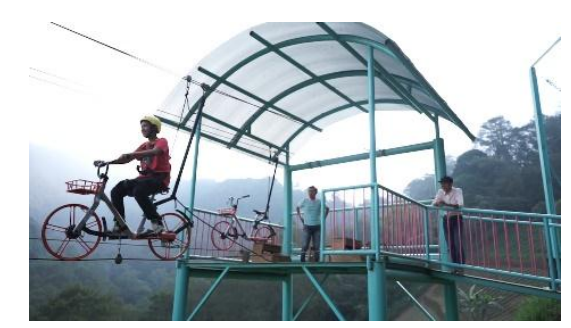

Gambar 18. Scene 6/EXT/Menampilkan Video Anak menaiki wahana Sky Bike/Day/Low Angle

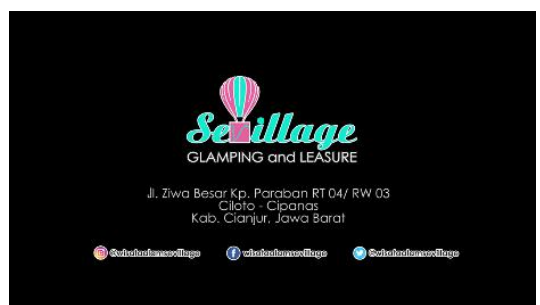

Gambar 20. Scene 8/ Menampilkan Logo Wisata Alam Sevillage, alamat, no telp, alamat dan media sosial.

\subsection{Post Production}

Post production merupakan tahapan akhir dari sebuah produksi yang sudah dikerjakan. Dimana tahapan ini adalah tahapan proses editing sebuah karya menjadi suatu Film yang utuh yang siap untuk dipublikasikan. Berikut tahapan-tahapan dari Post Production:

\section{Digitizing}

Tahapan Digitizing adalah tahapan proses perapihan dan pemindahan data dari kamera hasil shooting ke dalam laptop, untuk memilih pengambilan gambar dan angle yang terbaik yang akan digunakan. Tahapan digitizing ini bisa dilihat pada gambar 13 berikut:

2. Editing

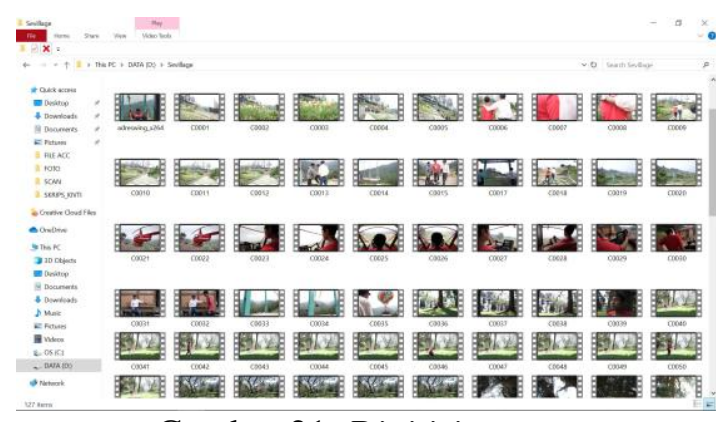

Gambar 21. Digitizing

Tahapan editing ini dilakukan setelah tahapan digitizing dan memerlukan waktu yang lama karena harus menyusun video dan memotong video sesuai dengan yang diinginkan untuk menghasilkan Film yang utuh. Pada tahap editing ini, editor 
menggunakan software Adobe Premiere CC 2018 dan beberapa software pendukung lainnya seperti yang ada pada gambar 14 dibawah ini:

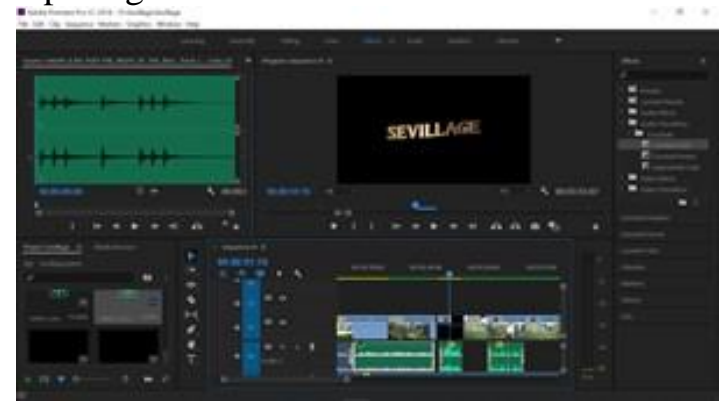

Gambar 22. Editing

3. $\quad$ Mixing

Mixing merupakan tahap penggabungan beberapa unsur audio visual seperti gambar, visual effect, dan backsound. Dengan penggabungan ini terciptalah Film Wisata Alam Sevillage yang jauh lebih menarik. Berikut gambar 15 tahapan mixing:

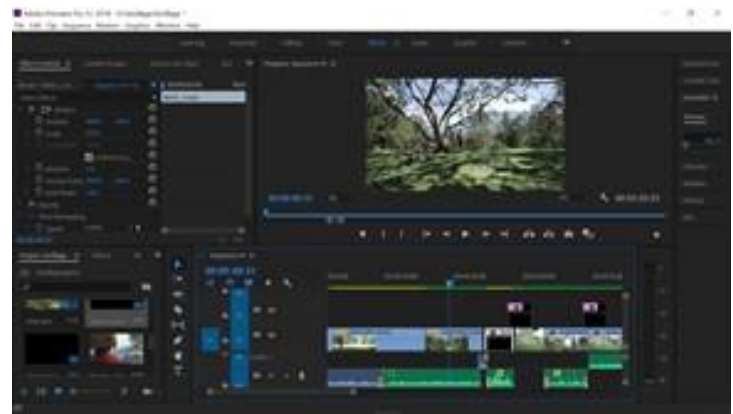

Gambar 23. Mixing

4. Finishing

Pada tahap finishing, Editor harus mengecek ulang agar tidak ada file video yang hilang atau rusak. Dan memastikan semua gambar, backsound dan visual effect tersusun rapi dan sesuai dengan susunan Pre Production (Storyboard, Sinopsis, dan Script Writing). Tahap finishing tertera pada gambar 16 berikut:

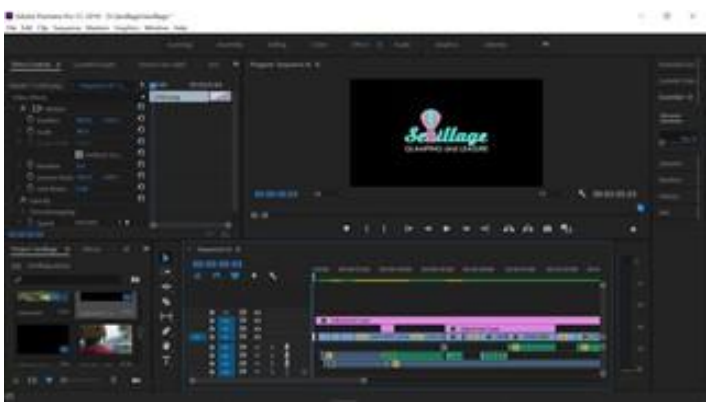

Gambar 24. Finishing

\section{Exporting}

Pada tahapan exporting adalah tahap terakhir setelah proses pembuatan suatu video. Jika video sudah selesai di-render dan siap untuk di export maka pada tahap ini menghasilkan video yang berkualitas baik. Pada tahap exporting Film Wisata Alam 
Sevillage Ciloto berkualitas Full HD 1920x1080 pixel seperti pada gambar 17 yang tertera dibawah ini:

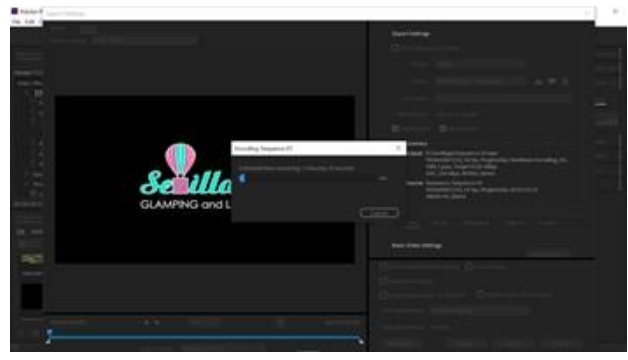

Gambar 25. Exporting

6. Segmen Pasar

Pada tahap segmen pasar ini merupakan tahapan target pasar yang akan dituju untuk menjangkau pangsa pasar daerah Kabupaten Cianjur, Jabodetabek dan jangkauan luas yaitu masyarakat seluruh Indonesia. Dengan adanya pemanfaatan Film pada Wisata Alam Sevillage Ciloto ini diharapkan akan menjadi daya tarik untuk meningkatan wisatawan yang ingin berkunjung dan ingin mengetahui tentang jenis-jenis kegiatan dan keunggulan pada Wisata Alam Sevillage Ciloto. Dan diharapkan dengan adanya Film ini juga mencapai target pasar, meningkatkan wisatawan yang sebelumnya pada tahun 2019 sebanyak 300500 orang perhari menurun menjadi 100-200 orang perhari, sehingga dengan adanya Film ini kedepannya diharapkan jumlah wisatawan bisa lebih meningkat lagi dari jumlah sebelumnya.

\section{KESIMPULAN}

Kesimpulan dari Film Wisata Alam Sevillage Ciloto ini adalah sebagai sarana meningkatkan daya tarik wisatawan untuk berkunjung, karena memiliki keunikan tersendiri dengan dikemas oleh teknik sinematografi yang indah dan menarik, sehingga orang yang menonton Film ini akan terbawa dengan suasana yang dibangun dalam Film. Strategi pemasaran yang digunakan yaitu implementasi Film ini melalui Youtube Channel Wisata Alam Sevillage Ciloto dan media sosial yaitu Facebook dan Instagram Wisata Alam Sevillage Ciloto, serta menampilkan Film ini pada setiap kegiatan atau event didalam maupun diluar Wisata Alam Sevillage Ciloto.

\section{SARAN}

Dengan adanya Film ini disarankan kepada Wisata Alam Sevillage Ciloto untuk terus mengembangkan media informasi dan promosi dengan konsep yang menarik, kreatif dan inovatif bagi wisatawan lokal maupun mancanegara untuk berwisata, dengan menambahkan dan mengembangkan lagi tampilan visual yang menarik dan informasi terupdate.

\section{DAFTAR PUSTAKA}

[1] Septian, I Gusti Ngurah Agung Pramasurya Dwi. Gede Saindra Santyadiputra. I Made Agus Wirawan. 2017. Film Dokumenter PTI : Rumahku (Sebuah Catatan, Sebuah Kisah). Bali : Universitas Pendidikan Ganesha. Jurnal Pendidikan Teknologi dan Kejuruan. ISSN: 2541-0652. Vol. 12, No. 2. 
[2] Santyadiputra, G. S., Pradnyana, G. A., \& Suardika, I. M. D. (2017). Film Dokumenter Genggong "Sebuah Instrumen Musik Kuno". Jurnal Nasional Pendidikan Teknik Informatika: JANAPATI, 6(1), 60-69.

[3] Hariyanto, A. F., Syafwandi, M. S., Afriwan, H., \& Sn, S. (2018). Perancangan Promosi Wisata Kota Medan Dalam Bentuk Media Audio Visual. DEKAVE: Jurnal Desain Komunikasi Visual, 7(2).

[4] Saleh, Y.R., Arya, I. F., \& Afriandi, I. (2016). Film yang Efektif Sebagai Media Promosi Kesehatan bagi Masyarakat. Jurnal Sistem Kesehatan, 2(2).

[5] Sari, R. D., Hasyim, A., \& Yanzi, H. (2017). Pemanfaatan Film Perjuangan untuk Meningkatkan Pemahaman Konsep Bela Negara Siswa. Jurnal Kultur Demokrasi, 5. 